\title{
A pilot study towards long-term thermal comfort research for lower-limb prosthesis wearers
}

\section{Abstract}

Background: Thermal discomfort amongst lower-limb prosthesis wearers is prevalent with social and medical consequences.

Objectives: This study aimed to verify the feasibility of out of laboratory thermal comfort studies.

Study design: Repeated measures pilot study

Methods: Thermistors were placed on participants' residual limbs during two experimental phases. In phase one, mean limb temperature was calculated over a controlled 55-minute rest-exercise-rest protocol. In phase two, participants conducted activities of their choosing wherever they wanted away from the lab, whilst limb temperature data was collected. Descriptive statistics and statistical differences between phases are presented.

Results: Five male amputees participated with an average age \pm SD of $30 \pm 9$ years. In phase one, mean limb temperature change ranged between $1.6^{\circ} \mathrm{C}$ to $3.7^{\circ} \mathrm{C}$. In phase two, mean limb temperature change ranged between $1.8{ }^{\circ} \mathrm{C}$ to $5.1{ }^{\circ} \mathrm{C}$. Limb temperature was significantly higher in out of lab studies $\left(+1.9{ }^{\circ} \mathrm{C}, \mathrm{p}\right.$ $=0.043$ ) compared to in-lab studies.

Conclusion: Independent multiple-hour temperature studies are shown to be feasible. Results also indicate that out of lab residual limb temperature can be significantly higher than in-lab temperatures.

Clinical Relevance: Thermal discomfort and sweating may lead to skin conditions and reduce quality of life amongst prosthesis wearers. Out of lab, long-term temperature studies are needed to comprehensively characterize thermal discomfort to create preventative solutions. 


\section{Background}

More than $50 \%$ of prosthesis wearers will suffer from overheating, excess sweating and thermal discomfort due to their prosthesis ${ }^{1}$. Amputees are susceptible to overheating and hyperhidrosis as thermoregulatory responses are less efficacious due to reduced body surface area ${ }^{2}$. Thermoregulation is also inhibited by prosthetic devices, as sockets and liners retain heat and sweat due to their low thermal conductivity ${ }^{2-4}$ and

impermeability ${ }^{5}$. Ultimately, this creates a hot and humid skin-prosthesis interface ${ }^{6-11}$ which may reduce prosthesis wear ${ }^{12}$ and as the interface is an ideal environment for bacteria, damaged skin may rapidly become infected ${ }^{8,13,14}$. Skin damage can take up to $177.6 \pm 113$ days to heal ${ }^{15}$, during which amputees may not be able to wear their prosthesis until the skin has fully recovered ${ }^{16}$. Bacteria can also cause unpleasant odors, which can lead to increased social anxiety and isolation ${ }^{17}$.

Previous prosthesis thermal comfort studies have been predominantly exploratory in nature and collected residual limb temperature data from male transtibial amputees in a laboratory setting ${ }^{6,7,18-20}$. All prior works have consisted of a 'rest-exercise-rest' protocol, with rest ranging from 15 - 60 minutes and treadmill ambulation ranging from $10-30$ minutes. Only one study explicitly controlled for environmental temperature, conducting testing at ambient temperatures of $10,15,20$ and $25^{\circ} \mathrm{C}^{19}$. Reported changes in mean residual limb temperature between the beginning and end of experiments have ranged from $1.7-3.1{ }^{\circ} \mathrm{C}$ ${ }^{6,7,19,20}$. These studies present small datasets collected from one participant ${ }^{7,19}$, five participants ${ }^{6}$, or up to nine participants ${ }^{20}$. The findings show that wearing a prosthesis and physical activity increases mean residual skin temperature. A study by Segal and Klute ${ }^{21}$ progressed the literature by conducting an out of lab study in a cold environment whilst doing physical exercise (snow-shoeing). Participants rested for 5 minutes, exercised for 30 minutes and rested for 5 minutes. A further exercise and rest period followed. Mean residual skin temperature increased by $3.9{ }^{\circ} \mathrm{C}$ between the start and end of the experiment. Segal and Klute also manually recorded perceived thermal comfort (PTC), ultimately finding that PTC was significantly associated with activity and rest. Their study is a commendable contribution to prosthesis thermal comfort, however, the environment and exercise studied are unlikely to reflect everyday activities for individuals living in more temperate climates. 
In light of the literature, we present a study which demonstrates a multi-hour research protocol conducted in a real-world environment, with full participant autonomy. We hypothesized that realism and participant freedom would uncover novel residual limb skin temperature behavior as a result of daily prosthesis wear. We highlight the importance of out of lab studies by conducting a controlled laboratory study and comparing data with out of lab data. Experiments were conducted in Japan during the month of August, where ambient temperatures were on average $30 \pm 3{ }^{\circ} \mathrm{C}^{22}$. Transfemoral amputees were predominantly recruited to provide insights from a previously untested participant group ${ }^{23}$. The combination of autonomous sensing, a realworld scenario and a rarely studied participant population mean that this study progresses lower-limb amputee thermal discomfort research. As research moves towards real-world, long-term studies, prosthetic devices that are thermally comfortable in a multitude of environmental and situational contexts becomes a realistic proposition.

\section{Methods:}

\section{Participants}

Ethical approval was obtained from the ethics boards of University College London and the National Rehabilitation Center for Persons with Disabilities, Tokorozawa, Japan. A convenience sampling approach was adopted to recruit male lower-limb amputees who wore a prosthesis daily. As the research team was all male, females were not recruited to reduce potential embarrassment while participants were in a state of undress when sensors were applied. Diabetic amputees were not recruited due to perceived additional skindamage risks.

\section{Protocol}

\section{Phase one}

The study comprised of two phases. The first phase obtained a standardized dataset for each participant and was conducted in a controlled air-conditioned laboratory environment. Participants were asked to remove 
their prosthesis and twelve thermistors were attached to the residuum using medical tape. Thermistors were placed within the lower, middle and top third of the residual limb, excluding the knee joint in transtibial amputees (Figure 1). Multiple thermistors provided insurance against thermistor failure. Thermistors were placed on fleshy parts of the residuum, avoiding bony prominences. Sensor attachment typically took 5 minutes and at most 10 minutes.

a) TFA

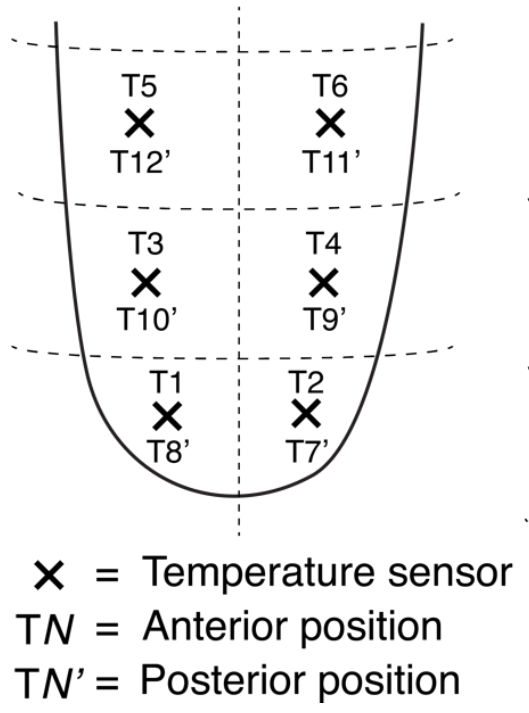

b) TTA

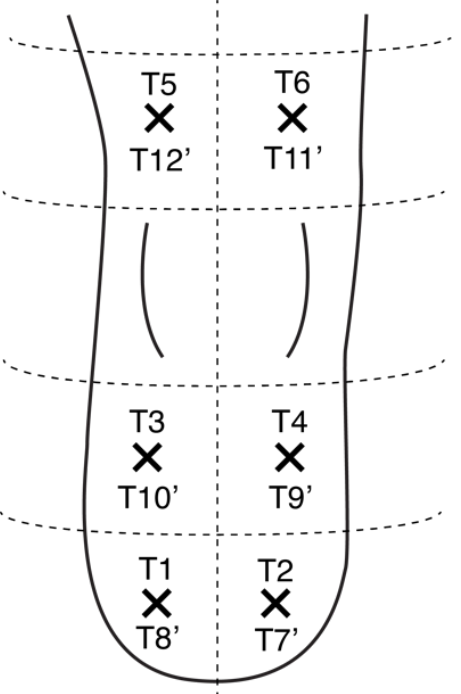

Figure 1: Temperature sensors were placed in similar positions as shown in the above diagram on both the anterior and posterior of the participants transfemoral (a) or transtibial (b) residual limb. For the TTA participant, sensors were not applied to the knee area to maintain mobility of the joint. TFA $=$ transfemoral amputee, TTA $=$ Transtibial amputee.

After attaching the sensors, participants donned their prosthesis and took a few supervised steps around the laboratory. Discomfort, pain and reductions in suspension were communicated and if present, the offending thermistor was repositioned. This process was repeated until no issues were present. The data logging system was then initiated. Participants were asked to sit and rest for 15 minutes, which allowed participants to relax and reduced limb heating effects caused by movement during thermistor application. Participants were then asked to walk for 10 minutes at a self-selected pace on a flat treadmill. Finally, participants were asked to sit for a further 30 minutes.

\section{Phase two}

On a different day to phase one, participants returned to the laboratory between 9-11 am to begin phase two.

The same sensor application procedure was used as in phase one. Once sensors were applied, the sensor 
system was turned on and participants could leave the laboratory and return when convenient. No contact was made with the participants until they returned to the lab and participants could conduct activities of their choosing. However, researchers were contactable if needed and it was made clear that sensors should be removed if they caused pain or discomfort. This autonomous phase empowered participants to take part in the experiment whilst going about natural activities in real-world environments without interruption.

\section{Temperature sensing system}

To collect temperature data, an Arduino MEGA 2560 microcontroller (Arduino, Italy) was connected to a DS1307 real-time clock (Maxim Integrated, USA) and an SD card reader. Sixteen B57863S103F40 NTC thermistors (Epcos, Germany) were connected to a linear potential divider (10 $\mathrm{k} \Omega \pm 1 \%$ tolerance resistors) and the system was powered by six AA $1.5 \mathrm{~V}$ batteries. New batteries were used for each study. The microcontroller was programmed using Arduino's integrated development environment (IDE) to acquire and save data at $1 \mathrm{~Hz}$. Thermistors were calibrated using the Steinhart-Hart equation and provided an absolute measurement accuracy of $\pm 0.2^{\circ} \mathrm{C}$ in a range between $0-70^{\circ} \mathrm{C}$. The data logger was placed into a waist bag and cables were routed under clothing so as to not be visible. Four thermistors positioned on the outside of the waist bag recorded ambient temperature.

\section{Statistical Analysis}

Matlab 2016a (Mathworks, USA) was used for analysis. Mean limb temperature over all thermistor locations provided a descriptive summary of residuum temperature behavior. If a thermistor broke during the experiment, data from that thermistor location were excluded from mean limb calculations. In phase one, switching between segments took no more than 30 seconds for all participants. To standardize timings, intermediate switching data was removed. During both phases, residual limb temperature averages of the first and last ten seconds of data were calculated to represent start and end temperatures. Finally, a Wilcoxon Signed-Rank test was implemented to assess differences between average limb temperatures in phase one and average limb temperatures in phase two, with a two-tailed p-value being reported and $95 \%$ CI, with significance determined when $\mathrm{p}<0.05$. 


\section{Results:}

In total, five male participants were recruited, with an average age \pm standard deviation of $30 \pm 9$ years. The time since amputation varied from 11 months to 37 years (congenital amputee). Table 1 describes basic participant characteristics. P2 used a walking aid and sensors were only applied to his transfemoral residual limb.

Table 1: Demographic and amputation information of the five participants that were recruited. Thermistors were applied to P2s right leg, which was a TFA.

\begin{tabular}{|c|c|c|c|c|c|c|c|}
\hline & Amputation level & Cause & $\begin{array}{l}\text { Time since } \\
\text { amputation }\end{array}$ & Prosthesis interface type & Age & Height & Weight \\
\hline $\mathrm{P} 1$ & - Left leg $\left(\mathrm{TFA}^{*}\right)$ & Trauma & $11 \mathrm{mo}$ & $\begin{array}{ll}\text { - } & \text { Suction socket } \\
\text { - } & \text { Össur ICEROSS TF seal } \\
& \text { in }\end{array}$ & 19 & $168 \mathrm{~cm}$ & $87 \mathrm{~kg}$ \\
\hline $\mathrm{P} 2$ & $\begin{array}{ll}\text { - } & \text { Left } \operatorname{arm}\left(\mathrm{SDi}^{\dagger}\right) \\
\text { - } & \text { Right } \operatorname{leg}\left(\mathrm{TFA}^{*}\right) \\
\text { - } & \text { Left leg }\left(\mathrm{TTA}^{\ddagger}\right)\end{array}$ & Trauma & $18 \mathrm{mo}$ & $\begin{array}{ll}\text { - } & \text { Suction socket } \\
\text { - } & \text { Össur ICEROSS X5 } \\
& \text { suction liner }\end{array}$ & 28 & $175 \mathrm{~cm}$ & - \\
\hline P3 & - Left leg $\left(\mathrm{TTA}^{\ddagger}\right)$ & Congenital & 37 yrs. & $\begin{array}{l}\text { PTB socket } \\
\text { - Ohio Willow Wood } \\
\text { Alpha classic ( } 3 \mathrm{~mm} \\
\text { thick) } \\
\text { - Alpha hybrid flex sleeve }\end{array}$ & 37 & $172 \mathrm{~cm}$ & $54 \mathrm{~kg}$ \\
\hline P4 & - Right leg (TFA* ${ }^{*}$ & Trauma & 6 yrs. & $\begin{array}{ll}\text { - } & \text { Suction socket } \\
\text { - } & \text { no liner }\end{array}$ & 42 & $168 \mathrm{~cm}$ & $80 \mathrm{~kg}$ \\
\hline P5 & - Right leg (TFA* $\left.{ }^{*}\right)$ & Trauma & 4 yrs. 6 mo. & $\begin{array}{ll}\text { - } & \text { Suction socket } \\
\text { - } & \text { Unbranded silicone liner }\end{array}$ & 25 & $175 \mathrm{~cm}$ & $57 \mathrm{~kg}$ \\
\hline
\end{tabular}

${ }^{*}$ TFA $=$ Transfemoral amputation, ${ }^{\dagger} \mathrm{SDi}=$ Shoulder Disarticulation, ${ }^{\ddagger}$ TTA $=$ Transtibial amputation

Segment-by-segment limb temperature changes from phase one data are presented in Table 2 and limb temperature data is presented as a time series in Figure 2. Some thermistor wires broke during the experiments (Table 2). The mean laboratory temperature was $26.7^{\circ} \mathrm{C}$. 
Table 2: Mean temperature data from the different parts of the first experimental phase are shown here \pm standard deviation for all participants. Changes in temperature $(\Delta)$ are calculated as the difference between the average of the last and first ten-seconds of temperature data in a segment of interest.

\begin{tabular}{ccccccccc}
\hline \hline & $\begin{array}{c}\text { Start Temp' } \\
\left({ }^{\circ} \mathrm{C}\right)\end{array}$ & $\begin{array}{c}\mathrm{R} 1 \Delta \mathrm{Temp} \\
\left({ }^{\circ} \mathrm{C}\right)\end{array}$ & $\begin{array}{c}\text { EXC } \Delta \text { Temp' } \\
\left({ }^{\circ} \mathrm{C}\right)\end{array}$ & $\begin{array}{c}\mathrm{R} 2 \Delta \mathrm{Temp} \\
\left({ }^{\circ} \mathrm{C}\right)\end{array}$ & $\begin{array}{c}\text { End Temp' } \\
\left({ }^{\circ} \mathrm{C}\right)\end{array}$ & $\begin{array}{c}\text { Mean Temp' } \\
\left({ }^{\circ} \mathrm{C}\right)\end{array}$ & $\begin{array}{c}\text { Start-End } \Delta \text { Temp' } \\
\left({ }^{\circ} \mathrm{C}\right)\end{array}$ & $\begin{array}{c}\text { Sensor } \\
\text { breakages }\end{array}$ \\
\hline $\mathrm{P} 1$ & $30.9 \pm 0.8$ & $1.8 \pm 0.005$ & $1.3 \pm 0.01$ & $0.5 \pm 0.01$ & $34.5 \pm 0.9$ & $33.5 \pm 1.1$ & $3.7 \pm 0.4$ & $\mathrm{~T} 7$ \\
$\mathrm{P} 2$ & $31.0 \pm 0.6$ & $0.6 \pm 0.006$ & $0.6 \pm 0.02$ & $0.5 \pm 0.01$ & $32.7 \pm 0.8$ & $32.1 \pm 0.5$ & $1.7 \pm 0.3$ & $\mathrm{~T} 1, \mathrm{~T} 3$ \\
$\mathrm{P} 3$ & $31.8 \pm 0.8$ & $0.4 \pm 0.003$ & $1.7 \pm 0.002$ & $0.3 \pm 0.01$ & $34.5 \pm 0.7$ & $33.5 \pm 1.1$ & $2.8 \pm 0.3$ & $\mathrm{~T} 1, \mathrm{~T} 7$ \\
$\mathrm{P} 4$ & $30.4 \pm 0.7$ & $0.8 \pm 0.001$ & $-0.1 \pm 0.004$ & $1.1 \pm 0.008$ & $32.3 \pm 0.7$ & $31.4 \pm 0.5$ & $2.0 \pm 0.3$ & $\mathrm{~T} 6$ \\
$\mathrm{P} 5$ & $31.6 \pm 0.5$ & $0.9 \pm 0.002$ & $0.3 \pm 0.001$ & $0.4 \pm 0.01$ & $33.2 \pm 1.2$ & $33.0 \pm 0.5$ & $1.6 \pm 0.4$ & $\mathrm{~T} 5$ \\
\hline \hline
\end{tabular}




\section{Phase 1: Limb temperature}
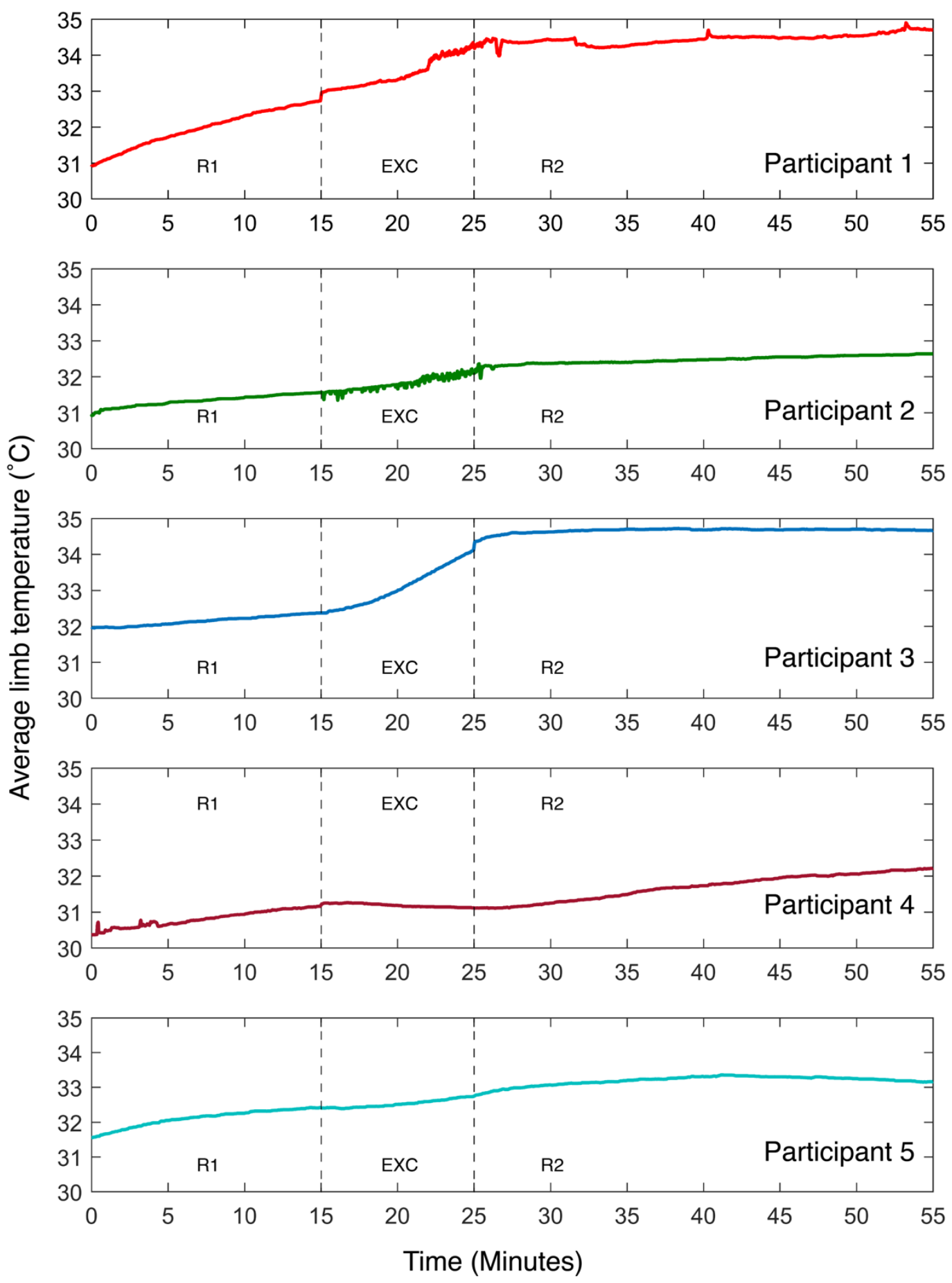

Figure 2. Residual limb temperature for each participant during phase one is shown as a time series. Each section of the protocol is labelled as rest 1 (R1), exercise (EXC) and rest 2 (R2.) 
Data from phase two are summarized in Table 3. The smallest change in limb temperature from the start-toend of the experiment was P4, with a change of only $1.8^{\circ} \mathrm{C}$ and P5 presented the largest change in limb temperature at $5.1{ }^{\circ} \mathrm{C}$. Again, some thermistor wires broke during the experiments (Table 3).

Table 3: Residual limb temperature and ambient temperature data were recorded for each participant during phase two of the experiment. To calculate the start and end temperature, the first and last ten seconds of limb temperature data were averaged.

\begin{tabular}{|c|c|c|c|c|c|c|c|}
\hline & $\begin{array}{l}\text { Start limb temp' } \\
\left({ }^{\circ} \mathrm{C}\right)\end{array}$ & $\begin{array}{l}\text { Mean limb temp' } \\
\left({ }^{\circ} \mathrm{C}\right)\end{array}$ & $\begin{array}{l}\text { End temp' } \\
\left({ }^{\circ} \mathrm{C}\right)\end{array}$ & $\begin{array}{c}\text { Temp' difference } \\
\left({ }^{\circ} \mathrm{C}\right)\end{array}$ & $\begin{array}{c}\text { Mean ambient } \\
\text { temp' }\left({ }^{\circ} \mathrm{C}\right)\end{array}$ & Duration & $\begin{array}{c}\text { Sensor } \\
\text { breakages }\end{array}$ \\
\hline $\mathrm{P} 1$ & $32.9 \pm 0.8$ & $35.9 \pm 0.8$ & $36.1 \pm 0.6$ & $3.2 \pm 0.3$ & $30.8 \pm 2.2$ & $4 \mathrm{~h} 27 \mathrm{~m}$ & $\mathrm{~T} 12$ \\
\hline $\mathrm{P} 2$ & $31.1 \pm 0.6$ & $33.9 \pm 1.2$ & $35.2 \pm 0.8$ & $4.1 \pm 0.3$ & $30.4 \pm 2.9$ & $2 \mathrm{~h} 22 \mathrm{~m}$ & - \\
\hline P3 & $32.3 \pm 0.4$ & $34.6 \pm 1.3$ & $37.2 \pm 0.2$ & $4.9 \pm 0.1$ & $28.5 \pm 1.8$ & $5 \mathrm{~h} 21 \mathrm{~m}$ & $\begin{array}{l}\text { T1, T7, } \\
\text { T8, T10 }\end{array}$ \\
\hline P4 & $31.7 \pm 0.7$ & $33.1 \pm 0.7$ & $33.6 \pm 0.7$ & $1.8 \pm 0.3$ & $27.6 \pm 2.3$ & $4 \mathrm{~h} 12 \mathrm{~m}$ & $\mathrm{~T} 5, \mathrm{~T} 7$ \\
\hline P5 & $32.1 \pm 0.5$ & $35.4 \pm 1.1$ & $37.3 \pm 0.8$ & $5.1 \pm 0.3$ & $33.0 \pm 2.7$ & $4 \mathrm{~h} 17 \mathrm{~m}$ & $\mathrm{~T} 5$ \\
\hline
\end{tabular}

To better understand the data corpus, temperature distributions of limb temperature during phase one and two, as well as ambient temperature during phase two, were plotted as a boxplot (Figure 3). A Wilcoxon Signed-ranks test revealed that experiments conducted away from the lab yielded significantly hotter mean

\section{Temperature Distributions for all datasets}

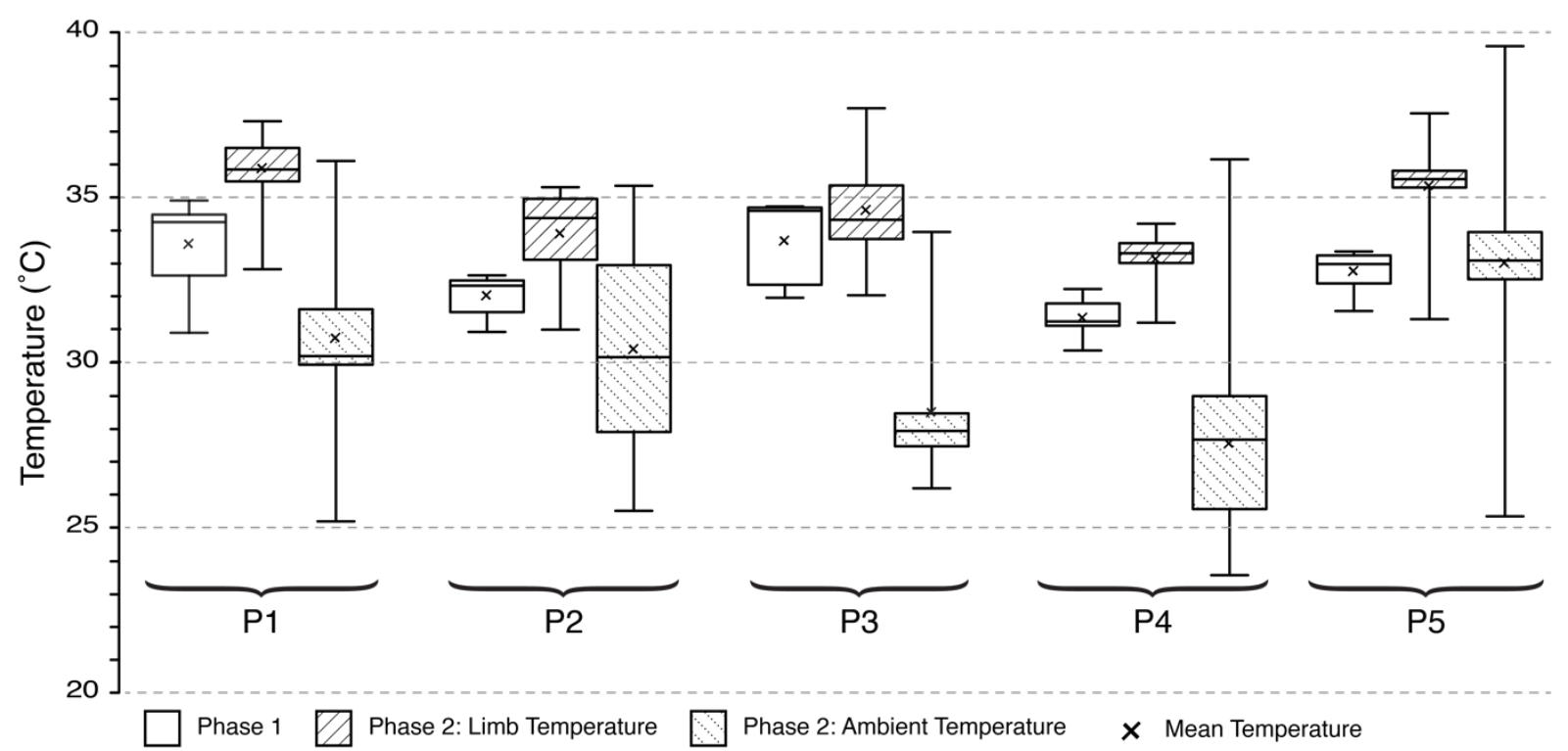

Figure 3: The residual limb temperature data from phase one and two as well as the ambient temperature data from phase two are displayed as a boxplot distribution for all participant datasets. 
residual limb temperatures than in lab tests $(Z=-2.023 \mathrm{p}=0.043)$, with an increase of $1.9{ }^{\circ} \mathrm{C}(95 \% \mathrm{CI}=1.2$ $\left.-2.6^{\circ} \mathrm{C}\right)$.

\section{Discussion:}

Heat and sweat discomfort in lower-limb prosthesis wearers is a prevalent and serious problem that must be addressed and although some solutions have been created ${ }^{24-27}$ their efficacy in the real world remains untested ${ }^{26,27}$, or they require further development ${ }^{24-26}$. Thermal discomfort studies have previously reported temperature changes seen in transtibial prosthesis wearers in laboratory settings, whilst performing controlled activities. A notable exception was the study by Segal and Klute, who investigated residual limb temperature in a cold non-laboratory environment ${ }^{21}$.

Our study collected data in a laboratory-based research scenario and an out of lab scenario and proves that it is possible to conduct multiple hour autonomous studies away from the lab and generate unique insights. Inlab data were collected over a 55-minute research protocol and out of laboratory data were collected between 2 hours and 22 minutes, to 5 hours and 21 minutes- dependent on participant schedules.

When reviewing phase one data, increases in residuum temperature are noticeable after donning the prosthesis - an observation first reported by Peery ${ }^{6}$. During the first rest phase, limb temperatures of all participants appear to steadily increase. It is likely that limb temperature would continue increasing up to a steady-state plateau if a long enough rest period were implemented. Most participants also displayed an increase in temperature during the exercise phase - something that was clearly demonstrated in P1 and P3. P4 did not display a clear change in limb temperature, which could be due to not wearing a liner. In future work, it may be interesting to explore if sustained rest whilst wearing a prosthesis incites similar elevated skin temperature levels as periods of exercise. In the final rest phase, all participants demonstrated a further increase in limb temperature with P1, P2, P3 and P5 approaching a plateau. Only P4 appeared as though their limb would continue increasing in temperature if the rest period continued. None of the participants' residual limbs returned to pre-exercise temperatures which demonstrates that heat is retained at the prosthesis-skin 
interface. Previous studies observed residual limb temperature changes ranging from $1.7-3.1^{\circ} \mathrm{C}$ in controlled laboratory settings ${ }^{6,720}$, however here, in similar conditions, the largest temperature change was $3.7^{\circ} \mathrm{C}(\mathrm{P} 1)$.

The box plot diagram shown in Figure 3 shows that all participant's residual limbs were, on average, hotter in the out of lab phase than in the in-lab phase. This is confirmed by a significant increase of $1.9{ }^{\circ} \mathrm{C}(95 \% \mathrm{CI}$ $=1.2-2.6{ }^{\circ} \mathrm{C}, \mathrm{p}=0.043$ ) between participants mean limb temperature in phase one and mean limb temperature in phase two. Differences in ambient temperatures between phases make this a relatively unsurprising finding, however, it subtly signifies the value of out-of-lab studies which have natural variety to prosthetic thermal comfort research. Additionally, during phase two, P5's residual limb changed temperature the most, at $5.1{ }^{\circ} \mathrm{C}$. This appears higher than increases found by Segal and Klute ${ }^{21}$, who found a mean residual limb temperature change of $3.9^{\circ} \mathrm{C}$. However, as only the mean residual limb temperature changes between subjects were reported and not the range, it is difficult to compare.

The data from our study will help inform the development of comfortable prostheses. However, the small participant size $(n=5)$ means that generalizations about the wider amputee population cannot be made. It is important to highlight that our participants were also relatively active and therefore, our findings may not translate to lower activity prosthesis wearers. One additional limitation inherent to most prosthetics research is that prosthesis prescription was not consistent between participants, as recruitment would have been prohibitively difficult. However, prescription differences do not reduce the validity of the presented findings. Finally, we contribute a number of practical considerations. Although our study suggests differences in mean residual limb temperature when comparing in-lab and out of lab environments, in-lab testing still has a place in future research. However, to progress prosthesis thermal comfort research, it may be beneficial to also consider simulating indoor activities such as task-based ambulation or leisure activities, rather than exclusively implementing treadmill ambulation. This will situate our understanding firmly in the real-world lived experience of prosthesis wearers. When designing out of laboratory protocols, researchers must acknowledge reductions in control. For example, participant autonomy means that researchers should not expect to control participants' activities, nor the environments that they encounter. Out of lab protocols, therefore, lend themselves to exploratory research, such as the study presented here. To account for reduced 
control, environmental sensors and activity monitors can provide useful additional data for analysis. Although the latter sensors were not used in this study, they would have added greater depth to the analysis. The impact of variety of activities and environmental contexts may also be mitigated by collecting data from participants at scale. For example, if experiments lasted multiple days, similar participants will likely experience comparable situations.

Long-term experiments still pose significant practical challenges. Although our study aimed to be minimally invasive and provided participants with more freedom than previous studies, sensor application is laborious and requires assistance. Thermistors are also prone to breakages, as demonstrated here and in other studies ${ }^{6,21}$. It is unclear how previous studies have handled thermistor breakages, however, we excluded broken thermistor data from mean limb temperature calculations. As residual limb temperature varies over the residuum surface ${ }^{6}$, this could introduce positive or negative bias to mean limb temperature calculations. However, in the majority of our experiments, no more than two thermistors broke, therefore, the consequences to mean limb temperature are likely minimal. In the case of PT3's phase two data, one anterior and three posterior thermistors broke. Therefore, the presented mean limb temperature may be lower than a mean limb value calculated if no thermistors had broken, as TTA posterior limb surfaces have been found to be warmer than anterior surfaces ${ }^{6}$. Multi-day or multi-week experiments, therefore, need robust temperature sensors that can be independently applied and removed by participants. Data collection systems also need to have high battery and data storage capacities for sustained data collection and recording. Small participant sizes also appear to be a common limitation in prosthetic thermal comfort research and thus the community should explore ways to safely lower participation barriers. One possible solution would be to devise ways for participants to independently apply sensors and to explore data redundancy ${ }^{28}$ between sensing sites to make application simpler. If these challenges can be overcome, long-term remote studies may become a feasible and safe reality. 


\section{Conclusion:}

Our study shows that it is possible to conduct autonomous out of lab temperature investigations among lowerlimb prosthesis wearers for multiple hours. In both experimental phases, residual limb temperature did not return to pre-prosthesis donning temperatures and residual limb temperature changes across both phases varied from $1.6{ }^{\circ} \mathrm{C}$ to $5.1{ }^{\circ} \mathrm{C}$. This appears higher than previous studies and raises the specification for future technologies that hope to prevent lower-limb prosthetic thermal discomfort. Thermal comfort research in real-world contexts may also provide valuable novel insights, as indicated by significant increases in mean limb temperature in real-world environments, compared to lab environments.

\section{Acknowledgements:}

We extend sincere thanks to the Japan Society for the Promotion of Science, who generously funded this research project as part of a 10-week summer fellowship.

All authors contributed equally in the preparation of this manuscript. 


\section{References:}

1. Ghoseiri K, Safari MR. Prevalence of heat and perspiration discomfort inside prostheses: Literature review. Journal of Rehabilitation Research and Development 2014; 51: 855-68.

2. Klute GK, Rowe GI, Mamishev AV, et al. The thermal conductivity of prosthetic sockets and liners. Prosthetics and Orthotics International 2007; 31: 292-299.

3. Klittich M, Davis B, Webber C, et al. Thermal conductivity of prosthetic elastomers, fabrics, liners, and socket materials. In: Proceedings of the 37th Annual Meeting of the American Society of Biomechanics, Omaha, NE. 2013.

4. Webber CM, Klittich MR, Dhinojwala A, et al. Thermal Conductivities of Commercially Available Prosthetic Materials: Journal of Prosthetics and Orthotics 2014; 26: 212-215.

5. Ruiz E. User Needs And Requirements For The Development Of A Moisture Permeable Prosthetic Interface. RESNA Student papers.

6. Peery JT, Ledoux WR, Klute GK. Residual-limb skin temperature in transtibial sockets. Journal of Rehabilitation Research and Development 2005; 42: 147-54.

7. Huff EA, Ledoux WR, Berge JS, et al. Measuring Residual Limb Skin Temperatures at the SkinProsthesis Interface: JPO Journal of Prosthetics and Orthotics 2008; 20: 170-173.

8. Meulenbelt HE, Geertzen JH, Jonkman MF, et al. Determinants of Skin Problems of the Stump in Lower-Limb Amputees. Archives of Physical Medicine and Rehabilitation 2009; 90: 74-81.

9. Hoaglund FT, Jergesen HE, Wilson L, et al. Evaluation of problems and needs of veteran lower-limb amputees in the San Francisco Bay Area during the period 1977-1980. J Rehabil R D 1983; 20: 5771.

10. Levy SW. Skin problems of the amputee. Warren H Green, 1983.

11. Levy SW. Amputees: skin problems and prostheses. Cutis 1995; 55: 297-301.

12. Meulenbelt HE, Geertzen JH, Jonkman MF, et al. Skin problems of the stump in lower limb amputees: 2. influence on functioning in daily life. Acta dermato-venereologica 2011; 91: 178-182.

13. Dudek NL, Marks MB, Marshall SC, et al. Dermatologic conditions associated with use of a lowerextremity prosthesis. Archives of Physical Medicine and Rehabilitation 2005; 86: 659-663.

14. Meulenbelt H, Geertzen J, Dijkstra P, et al. Skin problems in lower limb amputees: an overview by case reports. Journal of the European Academy of Dermatology and Venereology 2007; 21: 147-155.

15. Hoskins RD, Sutton EE, Kinor D, et al. Using vacuum-assisted suspension to manage residual limb wounds in persons with transtibial amputation: A case series. Prosthet Orthot Int 2013; 68-74.

16. Mak AFT, Zhang M, Boone DA. State-of-the-art research in lower-limb prosthetic biomechanicssocket interface: A review. Journal of Rehabilitation Research and Development 2001; 38: 161-74.

17. Saradjian A, Thompson AR, Datta D. The experience of men using an upper limb prosthesis following amputation: Positive coping and minimizing feeling different. Disability and Rehabilitation 2008; 30: 871-883. 
18. Peery JT, Klute GK, Blevins JJ, et al. A Three-Dimensional Finite Element Model of the Transibial Residual Limb and Prosthetic Socket to Predict Skin Temperatures. IEEE Transactions on Neural Systems and Rehabilitation Engineering 2006; 14: 336-343.

19. Mathur N, Glesk I, Buis A. Skin Temperature Prediction in Lower Limb Prostheses. IEEE Journal of Biomedical and Health Informatics 2014; 20: 158-165.

20. Klute GK, Huff E, Ledoux WR. Does Activity Affect Residual Limb Skin Temperatures? Clin Orthop Relat Res 2014; 472: 3062-3067.

21. Segal AD, Klute GK. Residual limb skin temperature and thermal comfort in people with amputation during activity in a cold environment. Journal of Rehabilitation Research and Development 2016; 53: 619-628.

22. Tokorozawa-shi Month Weather - AccuWeather Forecast for Saitama Japan. AccuWeather, http://www.accuweather.com/en/jp/tokorozawa-shi/225818/august-weather/225818 (accessed 4 January 2017).

23. Williams RJ, Washington ED, Miodownik M, et al. The effect of liner design and materials selection on prosthesis interface heat dissipation. Prosthetics and Orthotics International. Epub ahead of print 14 September 2017. DOI: 10.1177/0309364617729923.

24. Han Y, Liu F, Dowd G, et al. A thermal management device for a lower-limb prosthesis. Applied Thermal Engineering 2015; 82: 246-252.

25. Ghoseiri K, Zheng YP, Hing LLT, et al. The prototype of a thermoregulatory system for measurement and control of temperature inside prosthetic socket. Prosthet Orthot Int 2015; 0309364615588343.

26. Ghoseiri K, Zheng YP, Leung AKL, et al. Temperature Measurement and Control System for Transtibial Prostheses: Functional Evaluation. Assistive Technology. Epub ahead of print 3 October 2016. DOI: $10.1080 / 10400435.2016 .1225850$.

27. Wernke MM, Schroeder RM, Kelley CT, et al. SmartTemp Prosthetic Liner Significantly Reduces Residual Limb Temperature and Perspiration: Journal of Prosthetics and Orthotics 2015; 27: 134139.

28. Williams RJ, Holloway C, Miodownik M. The Ultimate Wearable: Connecting Prosthetic Limbs to the IoPH. In: Proceedings of the 2016 ACM International Joint Conference on Pervasive and Ubiquitous Computing: Adjunct. New York, NY, USA: ACM, pp. 1079-1083. 